OPEN ACCESS

Edited by:

Galila Agam,

Ben-Gurion University of the Negev,

Israel

Reviewed by:

Isabella Zanella,

University of Brescia, Italy

Jorge Matias-Guiu,

Complutense University of Madrid,

Spain

*Correspondence:

Francesco Fornai

francesco.fornai@neuromed.it,

francesco.fornai@med.unipi.it

tThese authors have contributed

equally to this work

Specialty section

This article was submitted to

Cellular Neuropathology,

a section of the journal

Frontiers in Cellular Neuroscience

Received: 14 August 2019

Accepted: 20 September 2019

Published: 04 October 2019

Citation:

Limanaqi F, Biagioni F, Ryskalin L, Busceti CL and Fornai F (2019) Molecular Mechanisms Linking ALS/FTD and Psychiatric Disorders, the Potential Effects of Lithium. Front. Cell. Neurosci. 13:450. doi: 10.3389/fncel.2019.00450

\section{Molecular Mechanisms Linking ALS/FTD and Psychiatric Disorders, the Potential Effects of Lithium}

\author{
Fiona Limanaqi ${ }^{1 \dagger}$, Francesca Biagioni ${ }^{2 \dagger}$, Larisa Ryskalin ${ }^{1}$, Carla L. Busceti ${ }^{2}$ and \\ Francesco Fornai ${ }^{1,2 *}$ \\ 1 Department of Translational Research and New Technologies in Medicine and Surgery, University of Pisa, Pisa, Italy, \\ 2 IRCCS Neuromed, Pozzilli, Italy
}

Altered proteostasis, endoplasmic reticulum (ER) stress, abnormal unfolded protein response (UPR), mitochondrial dysfunction and autophagy impairment are interconnected events, which contribute to the pathogenesis of amyotrophic lateral sclerosis (ALS)/frontotemporal dementia (FTD). In recent years, the mood stabilizer lithium was shown to potentially modify ALS/FTD beyond mood disorder-related pathology. The effects of lithium are significant in ALS patients carrying genetic variations in the UNC13 presynaptic protein, which occur in ALS/FTD and psychiatric disorders as well. In the brain, lithium modulates a number of biochemical pathways involved in synaptic plasticity, proteostasis, and neuronal survival. By targeting UPR-related events, namely ER stress, excitotoxicity and autophagy dysfunction, lithium produces plastic effects. These are likely to relate to neuroprotection, which was postulated for mood and motor neuron disorders. In the present manuscript, we try to identify and discuss potential mechanisms through which lithium copes concomitantly with ER stress, UPR and autophagy dysfunctions related to UNC13 synaptic alterations and aberrant RNA and protein processing. This may serve as a paradigm to provide novel insights into the neurobiology of ALS/FTD featuring early psychiatric disturbances.

Keywords: frontotemporal dementia, amyotrophic lateral sclerosis, bipolar disorder, endoplasmic reticulum stress, unfolded protein response, autophagy, Munc13, RNA processing

\section{INTRODUCTION}

Altered functioning of the endoplasmic reticulum (ER) may lead to the accumulation of misfolded proteins, which cause ER stress. This maybe due to either genetic defects or post-translational modifications(Senft and Ronai, 2015). To maintain cell viability, ER stress recruits an adaptive reaction, the unfolded protein response (UPR). The UPR triggers a network of signaling cascades, which inhibit protein translation while up-regulating protein folding chaperones and cell-clearing 
systems. This occurs through the activation of specific stress sensors, which control protein folding, ER biogenesis, protein trafficking to and from ER, proteasome-dependent ER-associated degradation, autophagy, and exosome secretion, among others. When chronic and severe ER stress occurs, the UPR switches into UPR-mediated cell death via apoptotic signaling, providing a common link in various CNS disorders (Matus et al., 2008). Despite being distinct in nosography, mood disorders and amyotrophic lateral sclerosis (ALS) may intersect at various biochemical levels where the UPR is involved, and comorbidity between these disorders often occurs (Zucchi et al., 2019). In fact, neuropsychiatric conditions are overrepresented in ALS patients and psychiatric symptoms may even precede the onset of motor symptoms. In detail, a diagnosis of schizophrenia-like psychosis, bipolar disorder, depression, or anxiety, which is often associated with a first diagnosis of ALS within the following 1-5 years, is likely to specifically reflect the clinicopathological overlap of ALS with frontotemporal dementia (FTD, Velakoulis et al., 2009a,b; Byrne et al., 2013; Turner et al., 2016; O’Brien et al., 2017). Beyond proteinopathy, ALS/FTD features early synaptic alterations, which are reminiscent of those occurring in psychiatric disorders (Casas et al., 2016; Bradshaw and Korth, 2019). Besides protein aggregation and toxicity, the ER, UPR and cell-clearing pathways are implicated in synaptic plasticity (Hetz, 2012; Limanaqi et al., 2018, 2019b; Martínez et al., 2018). Thus, in ALS/FTD spectrum, extracellular stressors and/or genetic defects may trigger synaptic and neuronal dysfunctions through altered proteostasis, yielding concomitant psychiatric and neurological symptoms. In recent years, the mood stabilizer lithium has shown therapeutic potential in both mood disorder-related pathology and ALS/FTD (Fornai et al., 2008a,b; Pasquali et al., 2009; Chiu et al., 2013; Berk et al., 2017; Devanand et al., 2017; van Eijk et al., 2017; Machado-Vieira, 2018; for ALS see Table 1). As shown by a recent clinical study, the disease-modifying effects of lithium are remarkably significant in ALS patients carrying genetic variations in the UNC13 presynaptic protein, which are associated with FTD, ALS/FTD spectrum and psychiatric disorders as well (Diekstra et al., 2014; Lipstein et al., 2017; Nakamura et al., 2018). Furthermore, patients with psychiatric disorders receiving regular lithium treatment have a reduced prevalence of ALS and dementia (Kessing et al., 2008; Prosser and Fieve, 2016). In the brain, lithium modulates a number of biochemical systems which are involved in synaptic plasticity, proteostasis, and neuronal survival, and which are placed downstream of two main targets, namely glycogen synthase kinase 3beta (GSK3 $\beta$ ) and mostly, phosphatidylinositol phosphatase pathway (Harwood, 2005; Pasquali et al., 2010a). By targeting UPR-related events, namely ER stress, excitotoxicity, and autophagy dysfunction either at the synapses or at cell bodies, lithium produces plastic effects on mood and motor activity, which may partly overlap with those responsible for neuroprotection. In the present minireview, we discuss specific molecular events related to alterations in UNC13 as well as RNA and protein processing, which can be potentially modified by lithium. Lessons from the effects of lithium in relation with ER stress, UPR and autophagy may serve as a paradigm to disclose potential neurobiological mechanisms, and hopefully, therapeutic targets in ALS/FTD.

\section{ER STRESS, UPR AND AUTOPHAGY IN ALS/FTD AND BIPOLAR DISORDER}

Endoplasmic reticulum stress and abnormal UPR play a central role in the pathogenesis of both psychiatric disease and ALS (Walker and Atkin, 2011; Cheng et al., 2014; Bengesser et al., 2016; Muneer and Shamsher Khan, 2019). Evidence for altered UPR in bipolar disorder stems from ex vivo studies documenting an abnormal response to ER stress-inducers. In detail, following stimulation with thapsigargin and tunicamycin, blood cells from bipolar patients show either unresponsive or reduced expression of the UPR markers p-eIF2 $\alpha$, GRP78, GRP94, XBP1, and CHOP (So et al., 2007; Hayashi et al., 2009; Pfaffenseller et al., 2014). Remarkably, changes in these markers predict lithium responsiveness in bipolar patients (Breen et al., 2016). This is not surprising since lithium may confer cytoprotection by recruiting these very same ER-stress related genes (Bown et al., 2000; Shao et al., 2006; Kakiuchi et al., 2009). Among bipolar patients, lithium was shown to be specifically effective in carriers with XBP1-116C allele, which has been identified as a risk factor for bipolar disorder (Masui et al., 2006).

In experimental ALS, ER stress increases the susceptibility of wild type SOD1 to aggregation (Medinas et al., 2018). Several UPR markers are increased in the spinal cord and blood of ALS patients and mouse models, with XBP1 activation representing an early pathological event in motor neuron disease (Ilieva et al., 2007; Atkin et al., 2008; Hetz et al., 2009; Ito et al., 2009; Matus et al., 2013; Montibeller and de Belleroche, 2018; Vats et al., 2018). As shown by in vitro studies, lithium may alleviate ER stress through GSK3 $\beta$ inhibition (Song et al., 2002; Takadera et al., 2007; Meares et al., 2008, 2011) and modulation of gene transcription via the PKC-GSK3 $\beta$-AP-1 axis (Boyle et al., 1991; Manji et al., 2001; Hiroi et al., 2005).

Unfolded protein response activation is known to induce autophagy (Rashid et al., 2015; Yan et al., 2015), which counteracts ER stress via degradation of protein aggregates and organelles including damaged mitochondria and ER. Nonetheless, autophagy alterations occur in both ALS/FTD and bipolar disorder (Fornai et al., 2008a; Pasquali et al., 2009; Ferrucci et al., 2011; Malhi et al., 2013; Kim et al., 2017; Ramesh and Pandey, 2017; Bar-Yosef et al., 2019; Deng et al., 2019), which may be associated at least in part, with an abnormal UPR response. For instance, despite being IRE1/XBP1 pathway generally considered as an autophagy inducer, XBP1s loss promotes FoxO1-dependent autophagy conferring neuroprotection in neurons (Vidal et al., 2012). Again, deletion of XBPI in SOD1 transgenic mice produces a phenotype, which is resistant to developing ALS, and this is associated with autophagy activation (Hetz et al., 2009; Matus et al., 2009). It is remarkable that lithium rescues autophagy failure occurring in both ALS/FTD and bipolar disorder (Fornai et al., 2008a,b; Malhi et al., 2013; Toker and Agam, 2014; Merenlender-Wagner et al., 2015; Natale et al., 2015; Kim et al., 2017; Ryskalin et al., 2018). This suggests that lithium may counteract ER stress and abnormal UPR through autophagy induction. As proof of concept, in vivo lithium administration decreases ER stressassociated proteins GRP78, ATF-6, and CHOP while promoting 
TABLE 1 | Clinical and experimental studies reporting beneficial effects of lithium in ALS.

ALS patients In vivo ALS models

16 ALS patients received riluzole plus lithium, and 28 received riluzole only. At 15 months, all 16 patients treated with lithium and riluzole were alive, whereas 8 of 28 treated only with riluzole died (survival rate 100 vs. $71 \%)$. Lithium delayed disease progression in ALS patients as assessed by quantitative measurement of the muscle strength (by the MRC scale) and preservation of the pulmonary function (by FVC) (Fornai et al., 2008a).
Lithium enhances survival and motor function while protecting spinal cord motor neurons in G93A-SOD-1 mice from oxidative stress and Fas-related apoptosis. These effects are potentiated upon combined treatment with lithium and the anti-oxidant agent Neu2000 (Shin et al., 2007).

Lithium delays the onset of disease symptoms prolonging the lifespan and decreasing the neurological deficit scores in G93A-SOD-1 mice while conferring neuroprotection through GSK3 inhibition in the brain and lumbar spinal cord. These effects are potentiated upon combined treatment with lithium and valproic acid (VPA, Feng et al., 2008).

Lithium confers neuroprotection, delays disease onset and duration and augments the life span in G93A SOD-1 mice, through activation of autophagy, stimulation of mitochondriogenesis, and suppression of reactive astrogliosis (Fornai et al., 2008a).
In vitro ALS models

Lithium pretreatment protects primary rat cerebellar granule against glutamate-induced excitotoxicity cells through GSK3 inhibition (Leng et al., 2008).

Lithium protects mice primary motor neurons and organotypic chick embryo spinal cord neurons against kainic acid-induced excitotoxicity through GSK3b inhibition and activation of autophagy (Calderó et al., 2010; Fulceri et al., 2011).
The study enrolled 18 ALS patients to be compared with 31 ALS out-patients. Lithium and valproate co-treatment significantly increased ALS patients' survival and exerted neuroprotection by increasing antioxidant defense markers assayed at baseline, and 5 and 9 months in plasma samples. The trial stopped after 21 months, due to the late adverse events of the treatment (Boll et al., 2014).

Data from 3 randomized trials on 518 participants showed that although lithium does not improve overall 12-month survival rate in the general ALS population, in UNC13A carriers, it increases the 12-month survival probability from $40.1 \%$ to $69.7 \%$ (van Eijk et al., 2017).

\begin{abstract}
Lithium attenuates neurodegeneration in the brainstem (trigeminal, facial, ambiguous, and hypoglossal nuclei) of G93A SOD-1 mice while rescuing hypoglossal recurrent collaterals (Ferrucci et al., 2010). Lithium induces mitophagy and mitochondriogenesis to reverse the severe subcellular pathology, which occurs mostly within peripheral motor axons and muscles of G93A SOD-1 mice (Natale et al., 2015).
\end{abstract}

Lithium protects primary cultures of embryo rat motor neurons from neurotoxicity which is induced by cerebrospinal fluids (CSFs) from ALS patients (Yáñez et al., 2014).

\begin{abstract}
Lithium suppresses the upregulation of Notch signaling and the postsynaptic protein Homer1b/c in the spinal cord of G93A SOD-1 mice to confer neuroprotection by increasing the $\mathrm{Bcl}-2 / \mathrm{Bax}$ ratio. These effects are potentiated upon combined treatment with lithium with VPA (Wang et al., 2015; Jiang et al., 2016).
\end{abstract}

\begin{abstract}
Lithium suppresses the upregulation of Notch signaling and the postsynaptic protein Homer $1 \mathrm{~b} / \mathrm{c}$ to confer cytoprotection in mtSOD1 (G93A) NSC34 cells (hybrid cell line of mouse neuroblastoma and embryonic spinal motor neurons) by increasing the $\mathrm{Bcl}-2 / \mathrm{Bax}$ ratio. These effects are potentiated upon combined treatment with VPA (Wang et al., 2015; Jiang et al., 2016).
\end{abstract}

the autophagy flux to protect motor neurons in the spinal cord (He et al., 2017; Tong et al., 2018).

\section{MUNC13 BRIDGING SYNAPTIC ALTERATIONS AND ER STRESS IN ALS/FTD AND BIPOLAR DISORDER}

Emerging evidence indicates a key role of the UPR in modulating synaptic function and connectivity. Altogether, ER proteostasis, UPR signaling, and cell clearing systems modulate behavior through intracellular pathways, which are involved in brain development and neuronal plasticity (Hetz, 2012; Limanaqi et al., 2018, 2019a,b; Martínez et al., 2018). In fact, the UPR in all its branches intermingles with the secretory pathway to finely tune the expression, synthesis, and folding of synaptic proteins. This occurs during their trafficking from ER, along with degradation by the proteasome and autophagy. Thus, UPR-related alterations may lead to synaptic remodeling and dysfunctions, which may occur independently of neurodegeneration (Hetz, 2012; Limanaqi et al., 2018, 2019a,b; Martínez et al., 2018). Detrimental changes in synaptic structure and function, namely synaptopathies, are considered as major contributors in psychiatric and neurological disorders (Lipstein et al., 2017; Limanaqi et al., 2018, 2019a,b; Ryskalin et al., 2018). This is best exemplified by alterations of Munc13, the mammalian ortholog of C. elegans unc13, which primes synaptic vesicles for exocytosis and regulates neurotransmitter release at presynaptic terminals and neuromuscular junctions. Gene variations/mutations in UNC13 occur in psychiatric conditions including bipolar disorder, as well as in ALS and FTD (van Es et al., 2009; Diekstra et al., 2014; Nakamura et al., 2018; Placek et al., 2019). Some UNC13 polymorphisms are associated with TDP-43 pathology underlying the ALS/FTD spectrum (Diekstra et al., 2014). In detail, UNC13A is associated with in vivo frontotemporal cortical atrophy, impaired cognitive performance, and greater burden of pTDP-43 pathological inclusions in sporadic ALS (Placek et al., 2019). Some variants in UNC13A are associated with increased disease prevalence and shorter survival in sporadic ALS patients (van Es et al., 2009; 
Diekstra et al., 2012; Yang et al., 2019). As recently described in a patient carrying a de novo UNC13 mutation, even subtle changes in Unc13 structure can be deleterious for synaptic transmission, leading to concomitant psychiatric and neurological deficits (Lipstein et al., 2017).

As shown by a recent introspective clinical study, the effects of lithium among ALS patients are remarkable in UNC13A carriers, leading to a $69.7 \%$ increase in the 12 -month survival rate (van Eijk et al., 2017). Therefore, in the present section we try to identify Munc13-related molecular events modified by lithium. In this context, it is fascinating that the regulatory domains of Munc13 are sensitive to lithium-dependent second messengers such as the phospholipase C (PLC)-inositol phosphate (IP3)/diacylglycerol (DAG, Brose et al., 1995).

\section{$\mathrm{Ca}^{2+}$ Signaling}

The behavioral phenotype caused by a gain of function Munc13 was recently explained by the presynaptic $\mathrm{Ca}^{2+}$ influx via voltagegated $\mathrm{Ca}^{2+}$ channels (VGCCs, Calloway et al., 2015; Lipstein et al., 2017). In detail, gene variations in Munc13 may affect its $\mathrm{Ca}^{2+}$ binding domain along with VGCC function leading an increased $\mathrm{Ca}^{2+}$ influx and synaptic vesicle exocytosis (Calloway et al., 2015). Dysregulation of $\mathrm{Ca}^{2+}$ homeostasis is prominent in both ALS and bipolar disorder (Machado-Vieira et al., 2011; Soeiro-de-Souza et al., 2012; Leal and Gomes, 2015; MachadoVieira, 2018). Altered $\mathrm{Ca}^{2+}$ homeostasis generates ER stress, mitochondrial dysfunction, altered UPR along with impaired autophagy flux (Kim et al., 2002; Kawamata and Manfredi, 2010; Pasquali et al., 2010a,b; Fulceri et al., 2011; Cozzolino and Carrì, 2012; Soeiro-de-Souza et al., 2012; Filippi-Chiela et al., 2016). In detail, following abnormal stimulation of G-coupled receptors at the plasma membrane, PLC is recruited to produce DAG, a Munc13 binding substrate, and $\mathrm{IP}_{3}$. The latter binds to IP3 receptors to release $\mathrm{Ca}^{2+}$ from ER stores. At the same time, $\mathrm{Ca}^{2+}$ acts as a Munc13 binding substrate, thus leading to a vicious cycle of Munc13-dependent $\mathrm{Ca}^{2+}$ influx and abnormal neurotransmitter release. The release of $\mathrm{Ca}^{2+}$ from ER is buffered by mitochondria, which over time may be damaged leading to reactive oxygen species (ROS) production. These events lead to protein misfolding, which exacerbates ER stress while activating the apoptotic branch of the UPR (Decuypere et al., 2011; Prell et al., 2013; Leal and Gomes, 2015).

Patch-clamp recording and $\mathrm{Ca}^{2+}$ imaging can be affected by lithium selectively in those neurons from lithium-responder bipolar patients (Mertens et al., 2015), since lithium tones down $\mathrm{Ca}^{2+}$-related oxidative stress and mitochondrial damage (Wasserman et al., 2004; Pasquali et al., 2010a,b; Fulceri et al., 2011; Leal and Gomes, 2015; Kim H. K. et al., 2016). In keeping with this, the effects of lithium on mitochondrial function are remarkable in both ALS and mood disorders (Kubota et al., 2006; Toker and Agam, 2014; Natale et al., 2015). In fact, lithium reverses the abnormal behaviors resembling mood disorder in transgenic mice with mitochondrial dysfunctions (Kubota et al., 2006), and bipolar lithium-responders possess normal levels of constitutive mitochondrial genes compared with poor lithium responders (Stacey et al., 2018). Again, through stimulation of mitophagy and mitochondriogenesis lithium reverses mitochondrial alterations, which are associated with motor neuron degeneration and distal axon clogging in ALS experimental models (Natale et al., 2015; Ruffoli et al., 2015). These effects of lithium may relate to inhibition of either GSK3 $\beta$ or PIP2 pathway, which are both linked to synaptic transmission, $\mathrm{Ca}^{2+}$ dynamics, ER and mitochondrial function, and autophagy modulation (Schlecker et al., 2006; Pasquali et al., 2010a,b; Decuypere et al., 2011; Ringsevjen et al., 2019). For instance, via inhibiting IP3 turnover and GSK3b, lithium activates NRF2 (Castillo-Quan et al., 2016), which orchestrates the fine dynamics between autophagy/mitophagy and mitochondriogenesis (Palikaras et al., 2015; Ruffoli et al., 2015).

\section{Diacylglycerol, the Paradigm of Munc13 and PKC}

Changes in DAG levels, which are produced by PLC at nerve terminals, are seminal to control the rate of neurotransmitter release through the activation of both Munc13 and protein kinase C (PKC, Nishizuka, 1992; Silinsky and Searl, 2003). Altered levels of DAG leading to abnormal activation of Munc13 and/or PKC converge into altering neurotransmitter release and $\mathrm{Ca}^{2+}$ influx. Alterations of PLC and DAG kinase are linked to mood disorders (Baum et al., 2008; Weber et al., 2011; Yang et al., 2016). Remarkably, PLC and DAG kinase may regulate mood through lithium-related pathways. In fact, ablation of PLC and/or DAG kinase produces a lithium-responsive mania-like behavior in animal models (Kakefuda et al., 2010; Isozaki et al., 2016; Yang et al., 2017).

The role of PLC/DAG-dependent alterations related to Munc13 in ALS/FTD remains unexplored. Nonetheless, it is tempting to speculate that alterations in PLC/DAG signaling play a role, since increased expression of PLC occurs within motor neurons of SOD1-G93A ALS mice. On the other hand, PLC ablation increases survival and reduces nuclear alterations within motor neurons (Staats et al., 2013). Thus, PLC may contribute to excitotoxicity either by increasing IP3 and $\mathrm{Ca}^{2+}$ release from $\mathrm{ER}$, or through DAG-dependent $\mathrm{Ca}^{2+}$ influx through Munc13 and $\mathrm{PKC}$ activation (Figure 1). Conversely, by reducing $\mathrm{PIP}_{2}-$ $\mathrm{IP}_{3} / \mathrm{DAG}$ levels, lithium is likely to reduce those intracellular alterations, which are due to the overlapping activities of PKC and Munc13 (Figure 1). Consistently with a reduced generation of DAG from $\mathrm{PIP}_{2}$ (Wang et al., 2001), lithium mitigates the expression and activity of $\mathrm{PKC}$, which occurs in patients with mood disorders (Manji and Lenox, 1999; Hahn et al., 2005). Lithium also inhibits PKC translocation to the plasma membrane while reducing its interaction with the receptor for activated C-kinase-1 (RACKS-1), which is enhanced in post-mortem brains of bipolar patients (Wang and Friedman, 2001). Besides mood disorders, increased levels and activity of PKC are detected in the cervical spinal cord of ALS patients compared with controls (Lanius et al., 1995; Wagey et al., 1998). Increased PKC activity may affect neuronal viability and foster disease progression (Krieger et al., 1996). This is shown in ALS mice, where increased expression of PKC occurs, leading to downregulation of the chloride channel 1 (ClC-1) (Camerino et al., 2019). Since ClC-1 


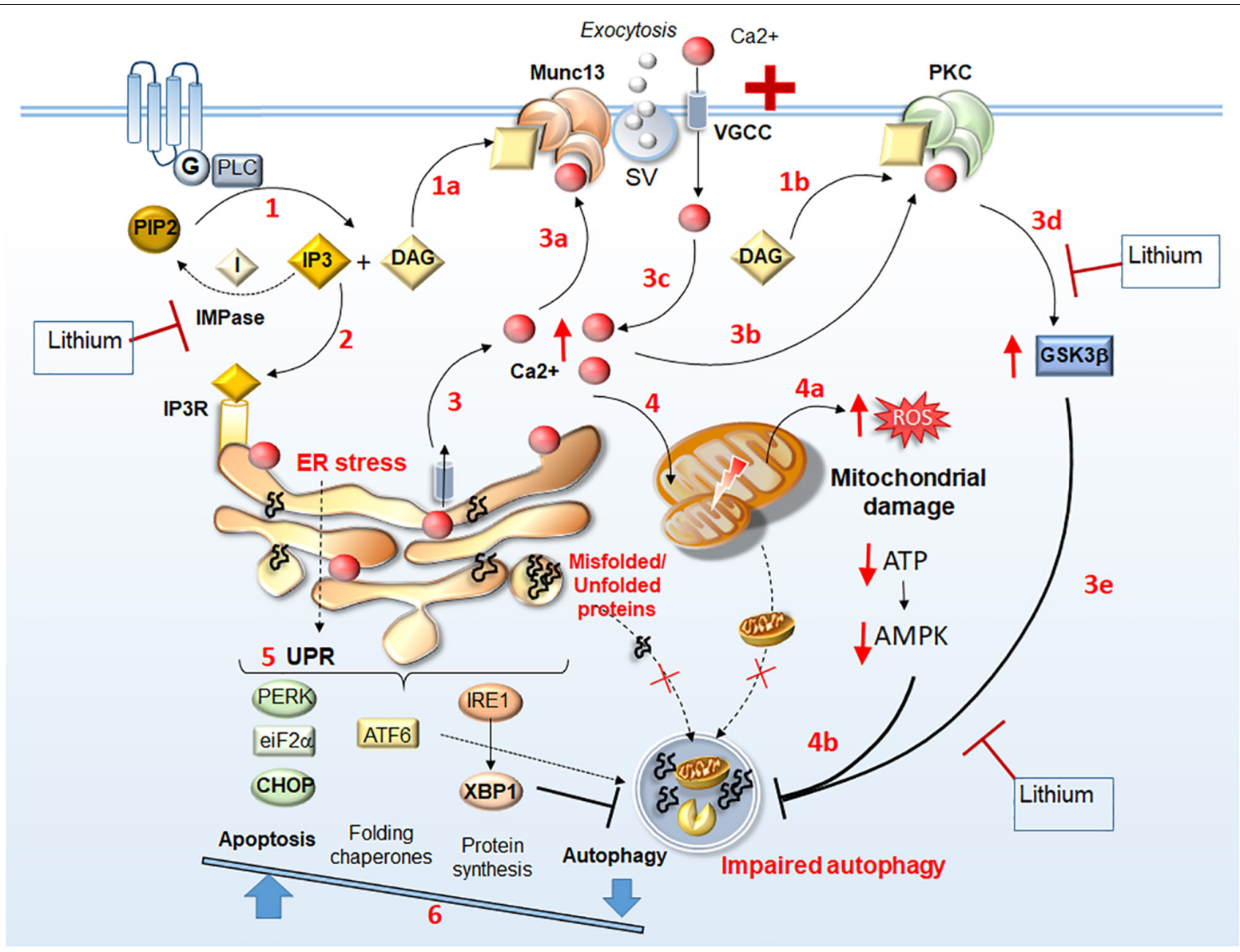

FIGURE 1 | Identifying lithium-sensitive events related to Munc13 and PKC alterations. Following stimulation of G-coupled receptors, PLC is recruited to produce $D A G$ and IP 3 (1). DAG acts a binding substrate for both Munc13 and PKC activation (1a, 1b, respectively), while IP3 binds to IP3 receptors (IP3R) on the ER (2) to mobilize $\mathrm{Ca}^{2+}$ from internal stores (3). This leads to an increase of intracellular $\mathrm{Ca}^{2+}$, which in turn, acts as a binding substrate for both Munc13 and PKC (3a, 3b, respectively). Abnormal Munc13 and PKC activation lead to abnormal neurotransmitter release (synaptic vesicle, SV exocytosis), further $\mathrm{Ca}^{2+}$ influx (3c), PKC-dependent GSK3 $\beta$ activation (3d), and subsequent autophagy impairment (3e). Thus, intracellular $\mathrm{Ca}^{2+}$ levels increase dramatically leading to ER stress, accumulation of unfolded/misfolded proteins within the ER, and mitochondrial damage (4) along with ROS production, ATP depletion and AMPK downregulation (4a), which contribute to impairing autophagy (4b). The UPR attempts to restore homeostasis by increasing protein folding and degradation while inhibiting protein synthesis through PERK/elF2a/CHOP, ATF6, and IRE1/XBP1 branches (5). Nonetheless, in conditions of a persistent ER stress, autophagy is also inhibited by XBP1, which shifts the UPR to apoptosis (6). Thus, misfolded/unfolded proteins and damaged mitochondria accumulate leading to a vicious cycle of chronic stress. Lithium may reverse these Munc13- and PKC-related molecular events either via GSK3 3 inhibition (steps 3d, 3e) or by reducing IP3 turnover through IMPase inhibition (steps 1, 2).

is key in sustaining neuromuscular junction and nerve integrity, its reduction leads to muscle hyper-excitability and impaired relaxation. Thus, PKC and Munc13 represent potential molecular targets in ALS (Varoqueaux et al., 2005; Veriepe et al., 2015; Camerino et al., 2019).

\section{Impaired Cell-Clearing Systems}

Ablation of Munc13 in ALS mice bearing the TDP-43A315T mutation is associated with decreased motor neuron degeneration compared with mice harboring A315T mutation alone (Veriepe et al., 2015). This is linked to abnormal Munc13-dependent exosome release, which may foster the exosome-mediated extracellular spreading of undigested TDP43 (Veriepe et al., 2015). Again, this is related to autophagy impairment, which may spread prion-like proteins via exocytosis
(Brundin et al., 2010), while lithium administration prevents the accumulation and spreading of prion-like proteins through induction of autophagy (Heiseke et al., 2009). Since proteasome and autophagy modulate neurotransmitter release and synaptic plasticity (Limanaqi et al., 2019a,b), a failure in the physiological turnover of Munc13 due to impaired cell-clearing pathways may lead to severe synaptic alterations.

\section{DYSFUNCTIONS OF RNA AND PROTEIN PROCESSING IN ALS/FTD AND MOOD DISORDERS}

Analysis of the genes and proteins at the heart of the continuum between ALS and FTD highlights a close connection between 
dysfunctions of RNA processing and autophagy as key events in disease pathophysiology (Thomas et al., 2013; Mandrioli et al., 2019). As support to such a functional convergence, a large amount of genes encoding proteins that are linked to ALS/FTD spectrum is involved in RNA metabolism and autophagy (Fornai et al., 2008b; Pasquali et al., 2010b; Mandrioli et al., 2019). This is best exemplified by mutations in TARDBP, FUS, and C9ORF72, which affect both global cellular RNA metabolism and autophagy. TARDBP, FUS, and C9ORF72 encode proteins with prion-like disordered domains, and dipeptide repeat polymers, respectively. These undergo phase separation to form stress granules (SGs) involving the UPR-related translation initiation factors eIF2 $\alpha$ and eIF3 (Colombrita et al., 2009; Ratti and Buratti, 2016; Boeynaems et al., 2017; Zhang et al., 2018; Mandrioli et al., 2019). Remarkably, structures being reminiscent of SG, which are composed of dipeptide repeat polymers co-localizing with ribosomal subunits and eIF3, were recently detected in the brain of c9ALS/FTD patients (Zhang et al., 2018). Although the role of SGs remains to be fully elucidated, TARDBP, FUS, and C9ORF72 mutations are suggested to impair both protein translation and autophagy-dependent SG degradation (Lee, 2015; Chitiprolu et al., 2018; Mandrioli et al., 2019). Thus, when UPR is aberrant and autophagy flux is impaired, SGs may persist giving rise to potentially toxic proteinaceous inclusions (Ryu et al., 2014; Lee, 2015; Monahan et al., 2016; Dimasi et al., 2017; Deng et al., 2019). As such, autophagy inducers represent a potential therapeutic strategy against altered SG processing in ALS/FTD. In keeping with this, it is interesting to note that lithium may induce autophagy through eIF $2 \alpha$ activation besides GSK3 $\beta$ inhibition (Relaño-Ginés et al., 2018). Even genes and proteins which are associated with bipolar disorder converge on UPR-related pathways controlling translation initiation and RNA processing (Carter, 2007; Darby et al., 2016; Laguesse and Ron, 2019). For instance, disrupted in schizophrenia 1 (DISC1) and neuregulin (NRG), which are implicated synaptic alterations and defective cytoskeleton-related organelle transport, induce eIF3dependent SG assembly in response to environmental stressors (Ogawa et al., 2005; Kim J.A. et al., 2016). NRG2 also localizes to SGs, and depletion of NRG2 inhibits SG aggregation to promote cell survival during ER stress (Kim J.A. et al., 2016). Remarkably, alterations of DISC1 and NRG may also affect autophagy, since both of them are associated with upstream signaling pathways, which converge on the AKT-GSK3 $\beta / \mathrm{mTOR}$ axis (Beaulieu, 2012; Ryskalin et al., 2018). NRG genetic variants are strongly associated with lithium responsiveness in mood disorders (Miranda et al., 2019); on the other hand, lithium normalizes the defective organelle transport caused by mutated DISC1 (Flores et al., 2011). In summary, these pieces of evidence

\section{REFERENCES}

Atkin, J. D., Farg, M. A., Walker, A. K., McLean, C., Tomas, D., and Horne, M. K. (2008). Endoplasmic reticulum stress and induction of the unfolded protein response in human sporadic amyotrophic lateral sclerosis. Neurobiol. Dis. 30, 400-407. doi: 10.1016/j.nbd.2008.02.009

Bar-Yosef, T., Damri, O., and Agam, G. (2019). Dual role of autophagy in diseases of the central nervous system. Front. Cell. Neurosci. 13:196. doi: 10.3389/fncel. 2019.00196 suggest that abnormal UPR, altered RNA and protein processing and autophagy impairment may represent a lithium-sensitive molecular cascade implicated in the neurobiology of ALS/FTD.

\section{CONCLUDING REMARKS}

Lithium remains the gold-standard therapeutic option for bipolar disorder. Despite years of inconclusive and disappointing results, lithium has been recently regarded as a potential neuroprotective drug in ALS, as shown by both translational and clinical studies. It is intriguing that the disease-modifying effects of lithium occur in a specific subpopulation of ALS patients bearing UNC13 variants, which it turn, are linked to bipolar disorder and ALS/FTD spectrum.

Lithium-sensitive psychiatric disorders, such as bipolar disorder, depression and anxiety may often precede ALS/FTD, and lithium prophylaxis in mood disorders is associated with reduced prevalence of ALS and dementia. In the present minireview, we discuss for the first time evidence suggesting that, at the molecular level lithium may target Unc13-related changes of synaptic activity, which produce concomitant neurological and psychiatric symptoms. The potential neuroprotective effects of lithium rely on the fact that it modulates several intracellular pathways involved in ER stress, $\mathrm{Ca}^{2+}$ toxicity, UPR, autophagy, and mitochondrial function. By rescuing the autophagy pathway, lithium may also target UPR-related dysfunctions of RNA and protein processing, which occur in bipolar disorder and most consistently, in ALS/FTD pathophysiology. Further studies elucidating the molecular mechanisms of action of lithium in relation with ER stress, UPR and autophagy, may disclose potential neurobiological mechanisms operating early in ALS/FTD and hopefully, preventive or therapeutic targets.

\section{AUTHOR CONTRIBUTIONS}

FL and FB drafted and wrote the manuscript, and contributed to the artwork. LR and CB made the literature research, manuscript editing, and contributed to the artwork. FF coordinator of the manuscript, he critically revised the manuscript for important intellectual content.

\section{FUNDING}

This work was supported by the Ministero Della Salute (Ricerca Corrente 2019).

Baum, A. E., Akula, N., Cabanero, M., Cardona, I., Corona, W., Klemens, B., et al. (2008). A genome-wide association study implicates diacylglycerol kinase eta (DGKH) and several other genes in the etiology of bipolar disorder. Mol. Psychiatry 13, 197-207. doi: 10.1038/sj.mp.4002012

Beaulieu, J. M. (2012). A role for Akt and glycogen synthase kinase-3 as integrators of dopamine and serotonin neurotransmission in mental health. J. Psychiatry Neurosci. 37, 7-16. doi: 10.1503/jpn.110011

Bengesser, S. A., Fuchs, R., Lackner, N., Birner, A., Reininghaus, B., Meier-Allard, N., et al. (2016). Endoplasmic reticulum stress and bipolar disorder - almost 
forgotten therapeutic drug targets in the unfolded protein response pathway revisited. CNS Neurol. Disord. Drug Targets 15, 403-413. doi: 10.2174/ 1871527315666160321104613

Berk, M., Dandash, O., Daglas, R., Cotton, S. M., Allott, K., Fornito, A., et al. (2017). Neuroprotection after a first episode of mania: a randomized controlled maintenance trial comparing the effects of lithium and quetiapine on grey and white matter volume. Transl. Psychiatry 7:e1011. doi: 10.1038/tp.2016.281

Boeynaems, S., Bogaert, E., Kovacs, D., Konijnenberg, A., Timmerman, E., Volkov, A., et al. (2017). Phase separation of C9orf72 dipeptide repeats perturbs stress granule dynamics. Mol. Cell 65, 1044.e-1055.e. doi: 10.1016/j.molcel.2017. 02.013

Boll, M. C., Bayliss, L., Vargas-Cañas, S., Burgos, J., Montes, S., Peñaloza-Solano, G., et al. (2014). Clinical and biological changes under treatment with lithium carbonate and valproic acid in sporadic amyotrophic lateral sclerosis. J. Neurol. Sci. 340, 103-108. doi: 10.1016/j.jns.2014.03.005

Bown, C. D., Wang, J. F., and Young, L. T. (2000). Increased expression of endoplasmic reticulum stress proteins following chronic valproate treatment of rat C6 glioma cells. Neuropharmacology 39, 2162-2169. doi: 10.1016/s00283908(00)00029-0

Boyle, W. J., Smeal, T., Defize, L. H., Angel, P., Woodgett, J. R., Karin, M., et al. (1991). Activation of protein kinase C decreases phosphorylation of c-Jun at sites that negatively regulate its DNA-binding activity. Cell 64, 573-584. doi: 10.1016/0092-8674(91)90241-p

Bradshaw, N. J., and Korth, C. (2019). Protein misassembly and aggregation as potential convergence points for non-genetic causes of chronic mental illness. Mol. Psychiatry 24, 936-951. doi: 10.1038/s41380-018-013 3-132

Breen, M. S., White, C. H., Shekhtman, T., Lin, K., Looney, D., Woelk, C. H., et al. (2016). Lithium-responsive genes and gene networks in bipolar disorder patient-derived lymphoblastoid cell lines. Pharmacogenomics J. 16, 446-453. doi: $10.1038 /$ tpj.2016.50

Brose, N., Hofmann, K., Hata, Y., and Südhof, T. C. (1995). Mammalian homologues of Caenorhabditis elegans unc-13 gene define novel family of C2domain proteins. J. Biol. Chem. 270, 25273-25280. doi: 10.1074/jbc.270.42. 25273

Brundin, P., Melki, R., and Kopito, R. (2010). Prion-like transmission of protein aggregates in neurodegenerative diseases. Nat. Rev. Mol. Cell. Biol. 11, 301-307. doi: $10.1038 / \mathrm{nrm} 2873$

Byrne, S., Heverin, M., Elamin, M., Bede, P., Lynch, C., Kenna, K., et al. (2013). Aggregation of neurologic and neuropsychiatric disease in amyotrophic lateral sclerosis kindreds: a population-based case-control cohort study of familial and sporadic amyotrophic lateral sclerosis. Ann. Neurol. 74, 699-708. doi: 10.1002/ ana. 23969

Calderó, J., Brunet, N., Tarabal, O., Piedrafita, L., Hereu, M., Ayala, V., et al. (2010). Lithium prevents excitotoxic cell death of motoneurons in organotypic slice cultures of spinal cord. Neuroscience 165, 1353-1369. doi: 10.1016/j. neuroscience.2009.11.034

Calloway, N., Gouzer, G., Xue, M., and Ryan, T. A. (2015). The active-zone protein Munc13 controls the use-dependence of presynaptic voltage-gated calcium channels. eLife. 21:4. doi: 10.7554/eLife.07728

Camerino, G. M., Fonzino, A., Conte, E., De Bellis, M., Mele, A., Liantonio, A., et al. (2019). Elucidating the contribution of skeletal muscle ion channels to amyotrophic lateral sclerosis in search of new therapeutic options. Sci. Rep. 9:3185. doi: 10.1038/s41598-019-39676-39673

Carter, C. J. (2007). Multiple genes and factors associated with bipolar disorder converge on growth factor and stress activated kinase pathways controlling translation initiation: implications for oligodendrocyte viability. Neurochem. Int. 50, 461-490. doi: 10.1016/j.neuint.2006.11.009

Casas, C., Manzano, R., Vaz, R., Osta, R., and Brites, D. (2016). Synaptic failure: focus in an integrative view of ALS. Brain Plast. 1, 159-175. doi: 10.3233/BPL140001

Castillo-Quan, J. I., Li, L., Kinghorn, K. J., Ivanov, D. K., Tain, L. S., Slack, C., et al. (2016). Lithium promotes longevity through GSK3/NRF2-dependent hormesis. Cell Rep. 15, 638-650. doi: 10.1016/j.celrep.2016.03.041

Cheng, D., Zhang, K., Zhen, G., and Xue, Z. (2014). The -116C/G polymorphism in XBP1 gene is associated with psychiatric illness in Asian population: a meta-analysis. Am. J. Med. Genet. B Neuropsychiatr. Genet. 165B, 665-672. doi: 10.1002/ajmg.b.32271
Chitiprolu, M., Jagow, C., Tremblay, V., Bondy-Chorney, E., Paris, G., Savard, A., et al. (2018). A complex of C9ORF72 and p62 uses arginine methylation to eliminate stress granules by autophagy. Nat. Commun. 9:2794. doi: 10.1038/ s41467-018-05273-5277

Chiu, C. T., Wang, Z., Hunsberger, J. G., and Chuang, D. M. (2013). Therapeutic potential of mood stabilizers lithium and valproic acid: beyond bipolar disorder. Pharmacol. Rev. 65, 105-142. doi: 10.1124/pr.111.005512

Colombrita, C., Zennaro, E., Fallini, C., Weber, M., Sommacal, A., Buratti, E., et al. (2009). TDP-43 is recruited to stress granules in conditions of oxidative insult. J. Neurochem. 111, 1051-1061. doi: 10.1111/j.1471-4159.2009.06383.x

Cozzolino, M., and Carrì, M. T. (2012). Mitochondrial dysfunction in ALS. Prog. Neurobiol. 97, 54-66. doi: 10.1016/j.pneurobio.2011.06.003

Darby, M. M., Yolken, R. H., and Sabunciyan, S. (2016). Consistently altered expression of gene sets in postmortem brains of individuals with major psychiatric disorders. Transl. Psychiatry. 6:e890. doi: 10.1038/tp.2016.173

Decuypere, J. P., Monaco, G., Bultynck, G., Missiaen, L., De Smedt, H., and Parys, J. B. (2011). The IP(3) receptor-mitochondria connection in apoptosis and autophagy. Biochim. Biophys. Acta 1813, 1003-1013. doi: 10.1016/j.bbamcr. 2010.11.023

Deng, Z., Lim, J., Wang, Q., Purtell, K., Wu, S., Palomo, G. M., et al. (2019). ALS-FTLD-linked mutations of SQSTM1/p62 disrupt selective autophagy and NFE2L2/NRF2 anti-oxidative stress pathway. Autophagy 30, 1-15. doi: 10.1080/ 15548627.2019.1644076

Devanand, D. P., Pelton, G. H., D’Antonio, K., Strickler, J. G., Kreisl, W. C., Noble, J., et al. (2017). Low-dose lithium treatment for agitation and psychosis in Alzheimer disease and frontotemporal dementia: a case series. Alzheimer Dis. Assoc. Disord. 31, 73-75. doi: 10.1097/WAD.0000000000000161

Diekstra, F. P., Van Deerlin, V. M., van Swieten, J. C., Al-Chalabi, A., Ludolph, A. C., Weishaupt, J. H., et al. (2014). C9orf72 and UNC13A are shared risk loci for amyotrophic lateral sclerosis and frontotemporal dementia: a genome-wide meta-analysis. Ann. Neurol. 76, 120-133. doi: 10.1002/ana.24198

Diekstra, F. P., van Vught, P. W., van Rheenen, W., Koppers, M., Pasterkamp, R. J., van Es, M. A., et al. (2012). UNC13A is a modifier of survival in amyotrophic lateral sclerosis. Neurobiol. Aging 33, 630.e3-630.e8. doi: 10.1016/ j.neurobiolaging.2011.10.029

Dimasi, P., Quintiero, A., Shelkovnikova, T. A., and Buchman, V. L. (2017). Modulation of p-eIF2 $\alpha$ cellular levels and stress granule assembly/disassembly by trehalose. Sci. Rep. 7:44088. doi: 10.1038/srep44088

Feng, H. L., Leng, Y., Ma, C. H., Zhang, J., Ren, M., and Chuang, D. M. (2008). Combined lithium and valproate treatment delays disease onset, reduces neurological deficits and prolongs survival in an amyotrophic lateral sclerosis mouse model. Neuroscience 155, 567-572. doi: 10.1016/j.neuroscience.2008. 06.040

Ferrucci, M., Fulceri, F., Toti, L., Soldani, P., Siciliano, G., Paparelli, A., et al. (2011). Protein clearing pathways in ALS. Arch. Ital. Biol. 149, 121-149. doi: 10.4449/aib.v149i1.1258

Ferrucci, M., Spalloni, A., Bartalucci, A., Cantafora, E., Fulceri, F., Nutini, M., et al. (2010). A systematic study of brainstem motor nuclei in a mouse model of ALS, the effects of lithium. Neurobiol. Dis. 37, 370-383. doi: 10.1016/j.nbd.2009. 10.017

Filippi-Chiela, E. C., Viegas, M. S., Thomé, M. P., Buffon, A., Wink, M. R., and Lenz, G. (2016). Modulation of autophagy by calcium signalosome in human disease. Mol. Pharmacol. 90, 371-384. doi: 10.1124/mol.116.105171

Flores, R., Hirota, Y., Armstrong, B., Sawa, A., and Tomoda, T. (2011). DISC1 regulates synaptic vesicle transport via a lithium-sensitive pathway. Neurosci. Res. 71, 71-77. doi: 10.1016/j.neures.2011.05.014

Fornai, F., Longone, P., Cafaro, L., Kastsiuchenka, O., Ferrucci, M., Manca, M. L., et al. (2008a). Lithium delays progression of amyotrophic lateral sclerosis. Proc. Natl. Acad. Sci. U.S.A. 105, 2052-2057. doi: 10.1073/pnas.070802 2105

Fornai, F., Longone, P., Ferrucci, M., Lenzi, P., Isidoro, C., Ruggieri, S., et al. (2008b). Autophagy and amyotrophic lateral sclerosis: the multiple roles of lithium. Autophagy 4, 527-530. doi: 10.4161/auto.5923

Fulceri, F., Ferrucci, M., Lazzeri, G., Paparelli, S., Bartalucci, A., Tamburini, I., et al. (2011). Autophagy activation in glutamate-induced motor neuron loss. Arch. Ital. Biol. 149, 101-111. doi: 10.4449/aib.v149i1.1259

Hahn, C. G., Umapathy, Wang, H. Y., Koneru, R., Levinson, D. F., and Friedman, E. (2005). Lithium and valproic acid treatments reduce PKC activation and 
receptor-G protein coupling in platelets of bipolar manic patients. J. Psychiatr. Res. 39, 355-363. doi: 10.1016/j.jpsychires.2004.10.007

Harwood, A. J. (2005). Lithium and bipolar mood disorder: the inositol-depletion hypothesis revisited. Mol. Psychiatry 10, 117-126. doi: 10.1038/sj.mp.4001618

Hayashi, A., Kasahara, T., Kametani, M., Toyota, T., Yoshikawa, T., and Kato, T. (2009). Aberrant endoplasmic reticulum stress response in lymphoblastoid cells from patients with bipolar disorder. Int. J. Neuropsychopharmacol. 12, 33-43. doi: $10.1017 /$ S1461145708009358

He, Z., Zhou, Y., Wang, Q., Li, J., Zheng, Z., Chen, J., et al. (2017). Inhibiting endoplasmic reticulum stress by lithium chloride contributes to the integrity of blood-spinal cord barrier and functional recovery after spinal cord injury. Am. J. Transl. Res. 9, 1012-1024.

Heiseke, A., Aguib, Y., Riemer, C., Baier, M., and Schätzl, H. M. (2009). Lithium induces clearance of protease resistant prion protein in prion-infected cells by induction of autophagy. J. Neurochem. 109, 25-34. doi: 10.1111/j.1471-4159. 2009.05906.x

Hetz, C. (2012). The unfolded protein response: controlling cell fate decisions under ER stress and beyond. Nat. Rev. Mol. Cell. Biol. 13, 89-102. doi: 10.1038/ nrm3270

Hetz, C., Thielen, P., Matus, S., Nassif, M., Court, F., Kiffin, R., et al. (2009). XBP-1 deficiency in the nervous system protects against amyotrophic lateral sclerosis by increasing autophagy. Genes Dev. 23, 2294-2306. doi: 10.1101/gad.1830709

Hiroi, T., Wei, H., Hough, C., Leeds, P., and Chuang, D. M. (2005). Protracted lithium treatment protects against the ER stress elicited by thapsigargin in rat PC12 cells: roles of intracellular calcium, GRP78 and Bcl-2. Pharmacogenomics J. 5, 102-111. doi: 10.1038/sj.tpj.6500296

Ilieva, E. V., Ayala, V., Jove, M., Dalfo, E., Cacabelos, D., Povedano, M., et al. (2007). Oxidative and endoplasmic reticulum stress interplay in sporadic amyotrophic lateral sclerosis. Brain 130, 3111-3123. doi: 10.1093/brain/awm190

Isozaki, T., Komenoi, S., Lu, Q., Usuki, T., Tomokata, S., Matsutomo, D., et al. (2016). Deficiency of diacylglycerol kinase $\eta$ induces lithium-sensitive manialike behavior. J. Neurochem. 138, 448-456. doi: 10.1111/jnc.13661

Ito, Y., Yamada, M., Tanaka, H., Aida, K., Tsuruma, K., Shimazawa, M., et al. (2009). Involvement of CHOP, an ER-stress apoptotic mediator, in both human sporadic ALS and ALS model mice. Neurobiol. Dis. 36, 470-476. doi: 10.1016/j. nbd.2009.08.013

Jiang, H. Z., Wang, S. Y., Yin, X., Jiang, H. Q., Wang, X. D., Wang, J., et al. (2016). Downregulation of Homer1b/c in SOD1 G93A Models of ALS: a novel mechanism of neuroprotective effect of lithium and valproic acid. Int. J. Mol. Sci. 17:E2129. doi: 10.3390/ijms17122129

Kakefuda, K., Oyagi, A., Ishisaka, M., Tsuruma, K., Shimazawa, M., Yokota, K., et al. (2010). Diacylglycerol kinase $\beta$ knockout mice exhibit lithiumsensitive behavioral abnormalities. PLoS One 5:e13447. doi: 10.1371/journal. pone. 0013447

Kakiuchi, C., Ishigaki, S., Oslowski, C. M., Fonseca, S. G., Kato, T., and Urano, F. (2009). Valproate, a mood stabilizer, induces WFS1 expression and modulates its interaction with ER stress protein GRP94. PLoS One 4:e4134. doi: 10.1371/ journal.pone.0004134

Kawamata, H., and Manfredi, G. (2010). Mitochondrial dysfunction and intracellular calcium dysregulation in ALS. Mech. Ageing Dev. 131, 517-526. doi: $10.1016 /$ j.mad.2010.05.003

Kessing, L. V., Søndergård, L., Forman, J. L., and Andersen, P. K. (2008). Lithium treatment and risk of dementia. Arch. Gen. Psychiatry 65, 1331-1335. doi: 10.1001/archpsyc.65.11.1331

Kim, H. K., Isaacs-Trepanier, C., Elmi, N., Rapoport, S. I., and Andreazza, A. C. (2016). Mitochondrial dysfunction and lipid peroxidation in rat frontal cortex by chronic NMDA administration can be partially prevented by lithium treatment. J. Psychiatr Res. 76, 59-65. doi: 10.1016/j.jpsychires.2016.02.001

Kim, J. A., Jayabalan, A. K., Kothandan, V. K., Mariappan, R., and Kee, Y. (2016). Identification of Neuregulin-2 as a novel stress granule component. BMB Rep. 49, 449-454. doi: 10.5483/bmbrep.2016.49.8.090

Kim, M. J., Jo, D. G., Hong, G. S., Kim, B. J., Lai, M., Cho, D. H., et al. (2002). Calpain-dependent cleavage of cain/cabin1 activates calcineurin to mediate calcium-triggered cell death. Proc. Natl. Acad. Sci. U.S.A. 99, 9870-9875. doi: 10.1073/pnas.152336999

Kim, Y., Santos, R., Gage, F. H., and Marchetto, M. C. (2017). Molecular mechanisms of bipolar disorder: progress made and future challenges. Front. Cell. Neurosci. 11:30. doi: 10.3389/fncel.2017.00030
Krieger, C., Lanius, R. A., Pelech, S. L., and Shaw, C. A. (1996). Amyotrophic lateral sclerosis: the involvement of intracellular $\mathrm{Ca} 2+$ and protein kinase C. Trends Pharmacol. Sci. 17, 114-120. doi: 10.1016/0165-6147(96)10004-3

Kubota, M., Kasahara, T., Nakamura, T., Ishiwata, M., Miyauchi, T., and Kato, T. (2006). Abnormal $\mathrm{Ca}^{2+}$ dynamics in transgenic mice with neuron-specific mitochondrial DNA defects. J. Neurosci. 26, 12314-12324. doi: 10.1523/ JNEUROSCI.3933-06.2006

Laguesse, S., and Ron, D. (2019). Protein translation and psychiatric disorders. Neuroscientist doi: 10.1177/1073858419853236 [Epub ahead of print].

Lanius, R. A., Paddon, H. B., Mezei, M., Wagey, R., Krieger, C., Pelech, S. L., et al. (1995). A role for amplified protein kinase C activity in the pathogenesis of amyotrophic lateral sclerosis. J. Neurochem. 65, 927-930. doi: 10.1046/j.14714159.1995.65020927.x

Leal, S. S., and Gomes, C. M. (2015). Calcium dysregulation links ALS defective proteins and motor neuron selective vulnerability. Front. Cell. Neurosci. 9:225. doi: $10.3389 /$ fncel.2015.00225

Lee, J. A. (2015). Autophagy manages disease-associated stress granules. Oncotarget 6, 30421-30422. doi: 10.18632/oncotarget.5902

Leng, Y., Liang, M. H., Ren, M., Marinova, Z., Leeds, P., and Chuang, D. M. (2008). Synergistic neuroprotective effects of lithium and valproic acid or other histone deacetylase inhibitors in neurons: roles of glycogen synthase kinase3 inhibition. J. Neurosci. 28, 2576-2588. doi: 10.1523/JNEUROSCI.5467-07. 2008

Limanaqi, F., Biagioni, F., Busceti, C. L., Ryskalin, L., and Fornai, F. (2019a). The effects of proteasome on baseline and methamphetamine-dependent dopamine transmission. Neurosci. Biobehav. Rev. 102, 308-317. doi: 10.1016/j.neubiorev. 2019.05.008

Limanaqi, F., Biagioni, F., Busceti, C. L., Ryskalin, L., Soldani, P., Frati, A., et al. (2019b). Cell clearing systems bridging neuro-immunity and synaptic plasticity. Int. J. Mol. Sci. 20:E2197. doi: 10.3390/ijms20092197

Limanaqi, F., Biagioni, F., Gambardella, S., Ryskalin, L., and Fornai, F. (2018). Interdependency between autophagy and synaptic vesicle trafficking: implications for dopamine release. Front. Mol. Neurosci. 11:299. doi: 10.3389/ fnmol.2018.00299

Lipstein, N., Verhoeven-Duif, N. M., Michelassi, F. E., Calloway, N., van Hasselt, P. M., Pienkowska, K., et al. (2017). Synaptic UNC13A protein variant causes increased neurotransmission and dyskinetic movement disorder. J. Clin. Invest. 127, 1005-1018. doi: 10.1172/JCI90259

Machado-Vieira, R. (2018). Lithium, stress, and resilience in bipolar disorder: deciphering this key homeostatic synaptic plasticity regulator. J. Affect. Disord. 233, 92-99. doi: 10.1016/j.jad.2017.12.026

Machado-Vieira, R., Pivovarova, N. B., Stanika, R. I., Yuan, P., Wang, Y., Zhou, R., et al. (2011). The Bcl-2 gene polymorphism rs956572AA increases inositol 1,4,5-trisphosphate receptor-mediated endoplasmic reticulum calcium release in subjects with bipolar disorder. Biol. Psychiatry 69, 344-352. doi: 10.1016/j. biopsych.2010.10.019

Malhi, G. S., Tanious, M., Das, P., Coulston, C. M., and Berk, M. (2013). Potential mechanisms of action of lithium in bipolar disorder. Current understanding. CNS Drugs 27, 135-153. doi: 10.1007/s40263-013-0039-30

Mandrioli, J., Mediani, L., Alberti, S., and Carra, S. (2019). ALS and FTD: where RNA metabolism meets protein quality control. Semin. Cell Dev. Biol. doi: 10.1016/j.semcdb.2019.06.003 [Epub ahead of print].

Manji, H. K., and Lenox, R. H. (1999). Ziskind-somerfeld research award. protein kinase $\mathrm{c}$ signaling in the brain: molecular transduction of mood stabilization in the treatment of manic-depressive illness. Biol. Psychiatry 46, 1328-1351. doi: 10.1016/s0006-3223(99)00235-8

Manji, H. K., Moore, G. J., and Chen, G. (2001). Bipolar disorder: leads from the molecular and cellular mechanisms of action of mood stabilizers. Br. J. Psychiatry Suppl. 41, s107-s119. doi: 10.1192/bjp.178.41.s107

Martínez, G., Khatiwada, S., Costa-Mattioli, M., and Hetz, C. (2018). ER proteostasis control of neuronal physiology and synaptic function. Trends Neurosci. 41, 610-624. doi: 10.1016/j.tins.2018.05.009

Masui, T., Hashimoto, R., Kusumi, I., Suzuki, K., Tanaka, T., Nakagawa, S., et al. (2006). A possible association between the $-116 \mathrm{C} / \mathrm{G}$ single nucleotide polymorphism of the XBP1 gene and lithium prophylaxis in bipolar disorder. Int. J. Neuropsychopharmacol. 9, 83-88.

Matus, S., Lisbona, F., Torres, M., León, C., Thielen, P., and Hetz, C. (2008). The stress rheostat: an interplay between the unfolded protein response (UPR) and 
autophagy in neurodegeneration. Curr. Mol. Med. 8, 157-172. doi: 10.1016/j. biopsych.2010.10.019

Matus, S., Nassif, M., Glimcher, L. H., and Hetz, C. (2009). XBP-1 deficiency in the nervous system reveals a homeostatic switch to activate autophagy. Autophagy 5, 1226-1228. doi: 10.4161/auto.5.8.10247

Matus, S., Valenzuela, V., Medinas, D. B., and Hetz, C. (2013). ER dysfunction and protein folding stress in ALS. Int. J. Cell. Biol. 2013:674751. doi: 10.1155/2013/ 674751

Meares, G. P., Mines, M. A., Beurel, E., Eom, T. Y., Song, L., Zmijewska, A. A., et al. (2011). Glycogen synthase kinase-3 regulates endoplasmic reticulum (ER) stress-induced CHOP expression in neuronal cells. Exp. Cell Res. 317, 1621-1628. doi: 10.1016/j.yexcr.2011.02.012

Meares, G. P., Zmijewska, A. A., and Jope, R. S. (2008). HSP105 interacts with GRP78 and GSK3 and promotes ER stress-induced caspase-3 activation. Cell Signal. 20, 347-358. doi: 10.1016/j.cellsig.2007.10.032

Medinas, D. B., Rozas, P., Martínez Traub, F., Woehlbier, U., Brown, R. H., Bosco, D. A., et al. (2018). Endoplasmic reticulum stress leads to accumulation of wildtype SOD1 aggregates associated with sporadic amyotrophic lateral sclerosis. Proc. Natl. Acad. Sci. U.S.A. 115, 8209-8214. doi: 10.1073/pnas.1801109115

Merenlender-Wagner, A., Malishkevich, A., Shemer, Z., Udawela, M., Gibbons, A., Scarr, E., et al. (2015). Autophagy has a key role in the pathophysiology of schizophrenia. Mol. Psychiatry 20, 126-132. doi: 10.1038/mp.2013.174

Mertens, J., Wang, Q. W., Kim, Y., Yu, D. X., Pham, S., Yang, B., et al. (2015). Differential responses to lithium in hyperexcitable neurons from patients with bipolar disorder. Nature 527, 95-99. doi: 10.1038/nature 15526

Miranda, A., Shekhtman, T., McCarthy, M., DeModena, A., Leckband, S. G., and Kelsoe, J. R. (2019). Study of 45 candidate genes suggests CACNG2 may be associated with lithium response in bipolar disorder. J. Affect. Disord. 248, 175-179. doi: 10.1016/j.jad.2019.01.010

Monahan, Z., Shewmaker, F., and Pandey, U. B. (2016). Stress granules at the intersection of autophagy and ALS. Brain Res. 1649, 189-200. doi: 10.1016/j. brainres.2016.05.022

Montibeller, L., and de Belleroche, J. (2018). Amyotrophic lateral sclerosis (ALS) and Alzheimer's disease (AD) are characterised by differential activation of ER stress pathways: focus on UPR target genes. Cell Stress Chaperones 23, 897-912. doi: 10.1007/s12192-018-0897-y

Muneer, A., and Shamsher Khan, R. M. (2019). Endoplasmic reticulum stress: implications for neuropsychiatric disorders. Chonnam. Med. J. 55, 8-19. doi: 10.4068/cmj.2019.55.1.8

Nakamura, T., Jimbo, K., Nakajima, K., Tsuboi, T., and Kato, T. (2018). De novo UNC13B mutation identified in a bipolar disorder patient increases a rare exonskipping variant. Neuropsychopharmacol. Rep. 38, 210-213. doi: 10.1002/npr2. 12027

Natale, G., Lenzi, P., Lazzeri, G., Falleni, A., Biagioni, F., Ryskalin, L., et al. (2015). Compartment-dependent mitochondrial alterations in experimental ALS, the effects of mitophagy and mitochondriogenesis. Front. Cell. Neurosci. 9:434. doi: 10.3389/fncel.2015.00434

Nishizuka, Y. (1992). Membrane phospholipid degradation and protein kinase C for cell signaling. Neurosci. Res. 15, 3-5. doi: 10.1016/0168-0102(92)90013-3

O’Brien, M., Burke, T., Heverin, M., Vajda, A., McLaughlin, R., Gibbons, J., et al. (2017). Clustering of neuropsychiatric disease in first-degree and seconddegree relatives of patients with amyotrophic lateral sclerosis. JAMA Neurol. 74, 1425-1430. doi: 10.1001/jamaneurol.2017.2699

Ogawa, F., Kasai, M., and Akiyama, T. (2005). A functional link between disruptedin-schizophrenia 1 and the eukaryotic translation initiation factor 3. Biochem. Biophys. Res. Commun. 338, 771-776. doi: 10.1097/WAD.0000000000000161

Palikaras, K., Lionaki, E., and Tavernarakis, N. (2015). Mitophagy: in sickness and in health. Mol. Cell Oncol. 3:e1056332. doi: 10.1080/23723556.2015.1056332

Pasquali, L., Busceti, C. L., Fulceri, F., Paparelli, A., and Fornai, F. (2010a). Intracellular pathways underlying the effects of lithium. Behav. Pharmacol. 21, 473-492. doi: 10.1097/FBP.0b013e32833da5da

Pasquali, L., Ruffoli, R., Fulceri, F., Pietracupa, S., Siciliano, G., Paparelli, A., et al. (2010b). The role of autophagy: what can be learned from the genetic forms of amyotrophic lateral sclerosis. CNS Neurol. Disord. Drug Targets 9, 268-278. doi: 10.2174/187152710791292594

Pasquali, L., Longone, P., Isidoro, C., Ruggieri, S., Paparelli, A., and Fornai, F. (2009). Autophagy, lithium, and amyotrophic lateral sclerosis. Muscle Nerve 40, 173-194. doi: 10.1002/mus.21423
Pfaffenseller, B., Wollenhaupt-Aguiar, B., Fries, G. R., Colpo, G. D., Burque, R. K., Bristot, G., et al. (2014). Impaired endoplasmic reticulum stress response in bipolar disorder: cellular evidence of illness progression. Int. J. Neuropsychopharmacol. 17, 1453-1463. doi: 10.1017/S1461145714000443

Placek, K., Baer, G. M., Elman, L., McCluskey, L., Hennessy, L., Ferraro, P. M., et al. (2019). UNC13A polymorphism contributes to frontotemporal disease in sporadic amyotrophic lateral sclerosis. Neurobiol. Aging 73, 190-199. doi: 10.1016/j.neurobiolaging.2018.09.031

Prell, T., Lautenschläger, J., and Grosskreutz, J. (2013). Calcium-dependent protein folding in amyotrophic lateral sclerosis. Cell Calcium 54, 132-143. doi: 10.1016/ j.ceca.2013.05.007

Prosser, J. M., and Fieve, R. R. (2016). Patients receiving lithium therapy have a reduced prevalence of neurological and cardiovascular disorders. Prog. Neuropsychopharmacol. Biol. Psychiatry. 71, 39-44. doi: 10.1016/j.pnpbp.2016. 06.006

Ramesh, N., and Pandey, U. B. (2017). Autophagy dysregulation in ALS: when protein aggregates get out of hand. Front. Mol. Neurosci. 10:263. doi: 10.3389/ fnmol.2017.00263

Rashid, H. O., Yadav, R. K., Kim, H. R., and Chae, H. J. (2015). ER stress: autophagy induction, inhibition and selection. Autophagy 11, 1956-1977. doi: 10.1080/ 15548627.2015.1091141

Ratti, A., and Buratti, E. (2016). Physiological functions and pathobiology of TDP-43 and FUS/TLS proteins. J. Neurochem. 138, 95-111. doi: 10.1111/jnc. 13625

Relaño-Ginés, A., Lehmann, S., Brillaud, E., Belondrade, M., Casanova, D., Hamela, C., et al. (2018). Lithium as a disease-modifying agent for prion diseases. Transl. Psychiatry 8:163. doi: 10.1038/s41398-018-0209-204

Ringsevjen, H., Umbach Hansen, H. M., Hussain, S., Hvalby, Ø, Jensen, V., Walaas, S. I, et al. (2019). Presynaptic increase in IP(3) receptor type 1 concentration in the early phase of hippocampal synaptic plasticity. Brain Res. 1706, 125-134. doi: 10.1016/j.brainres.2018.10.030

Ruffoli, R., Bartalucci, A., Frati, A., and Fornai, F. (2015). Ultrastructural studies of ALS mitochondria connect altered function and permeability with defects of mitophagy and mitochondriogenesis. Front. Cell. Neurosci. 9:341. doi: 10.3389/ fncel.2015.00341

Ryskalin, L., Limanaqi, F., Frati, A., Busceti, C. L., and Fornai, F. (2018). mTORrelated brain dysfunctions in neuropsychiatric disorders. Int. J. Mol. Sci. 19:E2226. doi: 10.3390/ijms19082226

Ryu, H.-H., Jun, M.-H., Min, K.-J., Jang, D.-J., Lee, Y.-S., Kim, H.-K., et al. (2014). Autophagy regulates amyotrophic lateral sclerosis-linked fused in sarcomapositive stress granules in neurons. Neurobiol. Aging. 35, 2822-2831. doi: 10. 1016/j.neurobiolaging.2014.07.026

Schlecker, C., Boehmerle, W., Jeromin, A., DeGray, B., Varshney, A., Sharma, Y., et al. (2006). Neuronal calcium sensor-1 enhancement of InsP3 receptor activity is inhibited by therapeutic levels of lithium. J. Clin. Invest. 116, 1668-1674. doi: 10.1172/JCI22466

Senft, D., and Ronai, Z. A. (2015). UPR, autophagy, and mitochondria crosstalk underlies the ER stress response. Trends Biochem. Sci. 40, 141-148. doi: 10.1016/ j.tibs.2015.01.002

Shao, L., Sun, X., Xu, L., Young, L. T., and Wang, J. F. (2006). Mood stabilizing drug lithium increases expression of endoplasmic reticulum stress proteins in primary cultured rat cerebral cortical cells. Life Sci. 78, 1317-1323. doi: 10.1016/j.lfs.2005.07.007

Shin, J. H., Cho, S. I., Lim, H. R., Lee, J. K., Lee, Y. A., Noh, J. S., et al. (2007). Concurrent administration of Neu2000 and lithium produces marked improvement of motor neuron survival, motor function, and mortality in a mouse model of amyotrophic lateral sclerosis. Mol. Pharmacol. 71, 965-975. doi: $10.1124 / \mathrm{mol} .106 .030676$

Silinsky, E. M., and Searl, T. J. (2003). Phorbol esters and neurotransmitter release: more than just protein kinase C? Br. J. Pharmacol. 138, 1191-1201. doi: 10.1038/ sj.bjp.0705213

So, J., Warsh, J. J., and Li, P. P. (2007). Impaired endoplasmic reticulum stress response in B-lymphoblasts from patients with bipolar-I disorder. Biol. Psychiatry 62, 141-147. doi: 10.1016/j.biopsych.2006.10.014

Soeiro-de-Souza, M. G., Dias, V. V., Figueira, M. L., Forlenza, O. V., Gattaz, W. F., Zarate, C. A. Jr., et al. (2012). Translating neurotrophic and cellular plasticity: from pathophysiology to improved therapeutics for bipolar disorder. Acta Psychiatr. Scand. 126, 332-341. doi: 10.1111/j.1600-0447.2012.01889.x 
Song, L., De Sarno, P., and Jope, R. S. (2002). Central role of glycogen synthase kinase- $3 \beta$ in endoplasmic reticulum stress-induced caspase- 3 activation. J. Biol. Chem. 277, 44701-44708. doi: 10.1074/jbc.m206047200

Staats, K. A., Van Helleputte, L., Jones, A. R., Bento-Abreu, A., Van Hoecke, A., Shatunov, A., et al. (2013). Genetic ablation of phospholipase C delta 1 increases survival in SOD1(G93A) mice. Neurobiol. Dis. 60, 11-17. doi: 10.1016/j.nbd. 2013.08.006

Stacey, D., Schubert, K. O., Clark, S. R., Amare, A. T., Milanesi, E., Maj, C., et al. (2018). A gene co-expression module implicating the mitochondrial electron transport chain is associated with long-term response to lithium treatment in bipolar affective disorder. Transl. Psychiatry 8:183. doi: 10.1038/s41398-0180237-230

Takadera, T., Fujibayashi, M., Kaniyu, H., Sakota, N., and Ohyashiki, T. (2007). Caspase-dependent apoptosis induced by thapsigargin was prevented by glycogen synthase kinase- 3 inhibitors in cultured rat cortical neurons. Neurochem. Res. 32, 1336-1342. doi: 10.1007/s11064-007-9 310-4

Thomas, M., Alegre-Abarrategui, J., and Wade-Martins, R. (2013). RNA dysfunction and aggrephagy at the centre of an amyotrophic lateral sclerosis/frontotemporal dementia disease continuum. Brain 136, 1345-1360. doi: 10.1093/brain/awt030

Toker, L., and Agam, G. (2014). Lithium, inositol and mitochondria. ACS Chem. Neurosci. 5, 411-412. doi: 10.1021/cn5001149

Tong, M., He, Z., Lin, X., Zhou, Y., Wang, Q., Zheng, Z., et al. (2018). Lithium chloride contributes to blood-spinal cord barrier integrity and functional recovery from spinal cord injury by stimulating autophagic flux. Biochem. Biophys. Res Commun. 495, 2525-2531. doi: 10.1016/j.bbrc.2017. 12.119

Turner, M. R., Goldacre, R., Talbot, K., and Goldacre, M. J. (2016). Psychiatric disorders prior to amyotrophic lateral sclerosis. Ann. Neurol. 80, 935-938. doi: 10.1002/ana.24801

van Eijk, R. P. A., Jones, A. R., Sproviero, W., Shatunov, A., Shaw, P. J., Leigh, P. N., et al. (2017). Meta-analysis of pharmacogenetic interactions in amyotrophic lateral sclerosis clinical trials. Neurology 89, 1915-1922. doi: 10.1212/WNL. 0000000000004606

van Es, M. A., Veldink, J. H., Saris, C. G., Blauw, H. M., van Vught, P. W., Birve, A., et al. (2009). Genome-wide association study identifies 19p13.3 (UNC13A) and 9p21.2 as susceptibility loci for sporadic amyotrophic lateral sclerosis. Nat. Genet. 41, 1083-1087. doi: 10.1038/ng.442

Varoqueaux, F., Sons, M. S., Plomp, J. J., and Brose, N. (2005). Aberrant morphology and residual transmitter release at the Munc13-deficient mouse neuromuscular synapse. Mol. Cell Biol. 25, 5973-5984. doi: 10.1128/MCB.25. 14.5973-5984.2005

Vats, A., Gourie-Devi, M., Ahuja, K., Sharma, A., Wajid, S., Ganguly, N. K., et al. (2018). Expression analysis of protein homeostasis pathways in the peripheral blood mononuclear cells of sporadic amyotrophic lateral sclerosis patients. J. Neurol. Sci. 387, 85-91. doi: 10.1016/j.jns.2018.01.035

Velakoulis, D., Walterfang, M., Mocellin, R., Pantelis, C., Dean, B., and McLean, C. (2009a). Abnormal hippocampal distribution of TDP-43 in patients withlate onset psychosis. Aust. N. Z. J. Psychiatry 43, 739-745. doi: 10.1080/ 00048670903001984

Velakoulis, D., Walterfang, M., Mocellin, R., Pantelis, C., and McLean, C. (2009b). Frontotemporal dementia presenting as schizophrenia-like psychosis in young people: clinicopathological series and review of cases. Br. J. Psychiatry 194, 298-305. doi: 10.1192/bjp.bp.108.057034

Veriepe, J., Fossouo, L., and Parker, J. A. (2015). Neurodegeneration in C. elegans models of ALS requires TIR-1/Sarm 1 immune pathway activation in neurons. Nat. Commun. 6:7319. doi: 10.1038/ncomms8319

Vidal, R. L., Figueroa, A., Court, F. A., Thielen, P., Molina, C., Wirth, C., et al. (2012). Targeting the UPR transcription factor XBP1 protects against Huntington's disease through the regulation of FoxO1 and autophagy. Hum. Mol. Genet. 21, 2245-2262. doi: $10.1093 / \mathrm{hmg} / \mathrm{dds} 040$
Wagey, R., Pelech, S. L., Duronio, V., and Krieger, C. (1998). Phosphatidylinositol 3-kinase: increased activity and protein level in amyotrophic lateral sclerosis. J. Neurochem. 71, 716-722. doi: 10.1046/j.1471-4159.1998.71020716.x

Walker, A. K., and Atkin, J. D. (2011). Stress signaling from the endoplasmic reticulum: a central player in the pathogenesis of amyotrophic lateral sclerosis. IUBMB Life 63, 754-763. doi: 10.1002/iub.520

Wang, H., and Friedman, E. (2001). Increased association of brain protein kinase C with the receptor for activated C kinase-1 (RACK1) in bipolar affective disorder. Biol. Psychiatry 50, 364-370. doi: 10.1016/s0006-3223(01)01147-7

Wang, H. Y., Johnson, G. P., and Friedman, E. (2001). Lithium treatment inhibits protein kinase C translocation in rat brain cortex. Psychopharmacology 158, 80-86. doi: 10.1007/s002130100834

Wang, S. Y., Ren, M., Jiang, H. Z., Wang, J., Jiang, H. Q., Yin, X., et al. (2015). Notch pathway is activated in cell culture and mouse models of mutant SOD1related familial amyotrophic lateral sclerosis, with suppression of its activation as an additional mechanism of neuroprotection for lithium and valproate. Neuroscience 301, 276-288. doi: 10.1016/j.neuroscience.2015.06.002

Wasserman, M. J., Corson, T. W., Sibony, D., Cooke, R. G., Parikh, S. V., Pennefather, P. S., et al. (2004). Chronic lithium treatment attenuates intracellular calcium mobilization. Neuropsychopharmacology 29, 759-769. doi: 10.1038/sj.npp.1300400

Weber, H., Kittel-Schneider, S., Gessner, A., Domschke, K., Neuner, M., Jacob, C. P., et al. (2011). Cross-disorder analysis of bipolar risk genes: further evidence of DGKH as a risk gene for bipolar disorder, but also unipolar depression and adult ADHD. Neuropsychopharmacology 36, 2076-2085. doi: 10.1038/npp.2011.98

Yan, M. M., Ni, J. D., Song, D., Ding, M., and Huang, J. (2015). Interplay between unfolded protein response and autophagy promotes tumor drug resistance. Oncol. Lett. 10, 1959-1969. doi: 10.3892/ol.2015.3508

Yáñez, M., Matías-Guiu, J., Arranz-Tagarro, J. A., Galán, L., Viña, D., GómezPinedo, U., et al. (2014). The neuroprotection exerted by memantine, minocycline and lithium, against neurotoxicity of CSF from patients with amyotrophic lateral sclerosis, is antagonized by riluzole. Neurodegener. Dis. 13, 171-179. doi: 10.1159/000357281

Yang, B., Jiang, H., Wang, F., Li, S., Wu, C., Bao, J., et al. (2019). UNC13A variant rs12608932 is associated with increased risk of amyotrophic lateral sclerosis and reduced patient survival: a meta-analysis. Neurol. Sci.doi: 10.1007/s10072-01903951-y [Epub ahead of print].

Yang, Y. R., Jung, J. H., Kim, S. J., Hamada, K., Suzuki, A., Kim, H. J., et al. (2017). Forebrain-specific ablation of phospholipase $C \gamma 1$ causes manic-like behavior. Mol. Psychiatry 22, 1473-1482. doi: 10.1038/mp.2016.261

Yang, Y. R., Kang, D. S., Lee, C., Seok, H., Follo, M. Y., Cocco, L., et al. (2016). Primary phospholipase C and brain disorders. Adv. Biol. Regul. 61, 80-85. doi: 10.1016/j.jbior.2015.11.003

Zhang, Y. J., Gendron, T. F., Ebbert, M. T. W., O'Raw, A. D., Yue, M., JansenWest, K., et al. (2018). Poly(GR) impairs protein translation and stress granule dynamics in C9orf72-associated frontotemporal dementia and amyotrophic lateral sclerosis. Nat. Med. 24, 1136-1142. doi: 10.1038/s41591-018-0071-1

Zucchi, E., Ticozzi, N., and Mandrioli, J. (2019). Psychiatric symptoms in amyotrophic lateral sclerosis: beyond a motor neuron disorder. Front. Neurosci. 13:175. doi: 10.3389/fnins.2019.00175

Conflict of Interest: The authors declare that the research was conducted in the absence of any commercial or financial relationships that could be construed as a potential conflict of interest.

Copyright (c) 2019 Limanaqi, Biagioni, Ryskalin, Busceti and Fornai. This is an open-access article distributed under the terms of the Creative Commons Attribution License (CC BY). The use, distribution or reproduction in other forums is permitted, provided the original author(s) and the copyright owner(s) are credited and that the original publication in this journal is cited, in accordance with accepted academic practice. No use, distribution or reproduction is permitted which does not comply with these terms. 